\title{
ISOPROSTANES - A NOVEL MAJOR GROUP OF OXIDATIVE STRESS MARKERS
}

\author{
MARTA CZERSKA, MAREK ZIELIŃSKI, and JOLANTA GROMADZIŃSKA
}

Nofer Institute of Occupational Medicine, Łódź, Poland

Department of Toxicology and Carcinogenesis

\begin{abstract}
Isoprostanes are a recently discovered group of prostaglandin isomers. Results of previous studies suggest that they can be used as oxidative stress markers, because in a number of cardiovascular, pulmonary and neurological diseases their levels in biological samples considerably increase. It has been found that people suffering from diabetes, obesity, homozygous familial hypercholesterolemia, moderate hypercholesterolemia, and smokers have higher levels of isoprostanes in urine. The same refers to patients with asthma, Alzheimer disease and Down syndrome. This paper reviews the results of relevant studies.
\end{abstract}

Key words:

Isoprostanes, Cardiovascular, Pulmonary, Neurological, Oxidative stress biomarkers, Asbestosis

\section{INTRODUCTION}

Isoprostanes (IsoP) are prostaglandin isomers produced in vivo from polyunsaturated fatty acids (mainly arachidonic acid) by a free radical catalyzed mechanism, which means that for their formation cyclooxygenases (COX-1 and COX-2) are not required [1,2]. The 1st IsoP class, discovered in 1990, were F2-isoprostanes [3]. Since that time, several other classes have been described: D2isoP, E2-isoP, A2-isoP and J2-isoP [4] and named according to the type of cyclopentane ring [5]. At present, there are 3 types of isoprostanes nomenclature: former nomenclature, Taber's nomenclature and Rokach's nomenclature [1].

There are some differences between prostaglandins (PG) and isoprostanes. While $\mathrm{PG}$ side chains are trans to the cyclopentane ring, isoprostane side chains are mainly cis isomers [4]. Prostaglandins are formed from free arachidonic acid, while isoprostanes are formed in situ in lipid membranes from polyunsaturated fatty acids, and then, they are released by phospholipases. It has also been reported that isoprostanes can be formed not only from arachidonic, but also from docosahexaenoic and eicosapentaenoic acids [6,7].

\section{OXIDATIVE STRESS}

Oxidative stress reflects imbalance between an increased exposure to reactive oxygen species (ROS) and antioxidant defense. Reactive oxygen species can be generated endogenously, but they can be also generated by exogenous factors such as radiation, tobacco smoke and drugs.

This study was carried out within the statutory project IMP.1.32. "The concentration of F2 isoprostane in biological samples of the Lodz healthy population." Project manager: Marek Zieliński, M.Sc.

Received: February 2, 2015. Accepted: May 9, 2015.

Corresponding author: M. Czerska, Nofer Institute of Occupational Medicine, Department of Toxicology and Carcinogenesis, Teresy 8, 91-348 Łódź, Poland (e-mail: czerskamar@gmail.com). 
It is known that oxidative stress is associated with many acute and chronic diseases, such as cancer and cardiovascular, neurodegenerative and lung diseases [8].

Nowadays, several in vitro oxidative stress markers are available, but they lack sensitivity and/or specificity, or require invasive methods [9].

\section{Isoprostanes as a marker of oxidative stress}

The first recognized use for isoprostanes was using them as mediators of oxidant stress [1]. Since they were discovered, the number of studies in which their authors have attempted to determine their levels in biological samples in clinical syndromes, probably associated with oxidative stress, has continued to increase. Till now, it is well known that IsoP levels are increased in biological samples in the case of a number of cardiovascular, pulmonary and neurological diseases [10,11].

The use of isoprostanes as markers of oxidative stress has several advantages over other oxidative stress markers, i.e., isoprostanes are chemically stable, they are specific products of peroxidation, they are formed in vivo, they are present in detectable amounts in tissues and biological fluids, and they are unaffected by lipid contents in a diet [9]. Because collection of urine is non-invasive and because isporostanes are very stable in urine, levels of isoprostanes are generally determined in this biological material [1].

\section{CARDIOVASCULAR DISEASES RISK FACTORS}

The main risk factors for heart disease include: hypercholesterolemia, diabetes, smoking, and obesity [10,11]. It has been found that in humans with a number of those risk factors, the level of IsoPs formation is elevated [11].

Gopaul et al. [12] have analyzed plasma levels of 8-epi$\mathrm{PGF}_{2 \alpha}$ in non-insulin dependent diabetes mellitus (NIDDM, diabetes type 2) and compared them with healthy individuals. Levels of 8-epi-PGF ${ }_{2 \alpha}$ in plasma samples from the diabetic individuals $(\mathrm{N}=39)$ were higher $(0.49-2.16 \mathrm{nM})$ than in the control group $(\mathrm{N}=16)$
$(0.02-0.63 \mathrm{nM})$. Davi et al. [13] have received similar results. Levels of urinary 8-iso-PGF ${ }_{2 a}$ in patients with NID$\mathrm{DM}(\mathrm{N}=62,419 \pm 208 \mathrm{pg} / \mathrm{mg}$ creatinine $)$ were significantly higher $(\mathrm{p}=0.0001)$ than in age-matched healthy subjects $(208 \pm 92 \mathrm{pg} / \mathrm{mg}$ creatinine). The authors have also investigated urinary 8 -iso- $\mathrm{PGF}_{2 \alpha}$ levels in patients with insulin dependent diabetes mellitus (IDDM, diabetes type 1). In those patients the urinary 8-iso- $\mathrm{PGF}_{2 \alpha}$ levels were also higher ( $\mathrm{N}=23,400 \pm 146 \mathrm{pg} / \mathrm{mg}$ creatinine) compared to those of controls (197 $\pm 69 \mathrm{pg} / \mathrm{mg}$ creatinine, $\mathrm{p}=00001)$. Also Keaney et al. have found out that diabetes is strongly and positively associated with urinary 8-epi-PGF ${ }_{2 \alpha}$ levels [14]. Davi et al. suggest that in diabetes type 1 in children and adolescents, IsoPs formation increases in an early stage of the disease and decreases as the disease progresses [15].

Nowadays, the number of people who suffer from obesity is still increasing. Obesity is one of the causes of atherosclerotic cardiovascular disease. Keaney et al. [14] have investigated the correlation between body mass index (BMI) and urinary 8-epi-PGF ${ }_{2 \alpha}$ levels in nearly 3000 Framingham Heart Study participants. The results show that there is a strong association between BMI and urinary 8-epi$\mathrm{PGF}_{2 \alpha}$ levels [14]. Also Davi et al. [16] in their study have found an association between 8-iso-PGF ${ }_{2 \alpha}$ and obesity. In that study, the authors have also observed that in the android obesity, urinary 8-iso- $\mathrm{PGF}_{2 \alpha}$ levels are higher than in the gynoid obesity $(\mathrm{p}<0.001)$. What is more, other authors have observed that reduction of BMI leads to a decrease in 8-iso- $\mathrm{PGF}_{2 \alpha}$ urinary levels [16].

It is generally recognized that tobacco smoking leads to cardiovascular diseases, however, the underlying mechanism is not fully understood [11]. Morrow et al. have investigated the correlation between smoking status and levels of free $\mathrm{F}_{2}$-isoprostanes in plasma and of $\mathrm{F}_{2}$-isoprostanes esterified to lipids in plasma [3]. In a pilot study with 16 smokers and 8 age-matched nonsmokers, the levels of free plasma $\mathrm{F}_{2}$-isoprostanes in 
the smokers samples $(166 \pm 58 \mathrm{pmol} / \mathrm{l})$ were significantly higher $(p=0.02)$ than in the age- and sex-matched nonsmokers $(90 \pm 52 \mathrm{pmol} / \mathrm{l})$. The levels of $\mathrm{F}_{2}$-isoprostanes esterified to lipids were also significantly higher $(p=0.05)$ in the smokers $(496 \pm 276 \mathrm{pmol} / \mathrm{l})$ when compared to the non-smoker samples $(290 \pm 90 \mathrm{pmol} / \mathrm{l})$.

In a validation study, which was conducted to confirm the results of the pilot study and to determine shortterm effects of smoking and effects of abstinence from smoking for $\mathrm{F}_{2}$-isoprostanes levels, the participants were 10 smokers (5 males, 5 females) and 10 nonsmokers (5 males, 5 females). The results of free plasma $\mathrm{F}_{2}$-isoprostane levels and levels of $\mathrm{F}_{2}$-isoprostanes esterified to lipids in plasma were the same as in the pilot study: the levels of free isoprostanes in the smokers $(242 \pm 147 \mathrm{pmol} / \mathrm{l})$ were significantly higher $(p=0.02)$ than in the non-smokers $(103 \pm 19 \mathrm{pmol} / \mathrm{l})$. The levels of $\mathrm{F}_{2}$-isoprostanes esterified to lipids in the smokers $(574 \pm 217 \mathrm{pmol} / \mathrm{l})$ were also significantly higher $(\mathrm{p}=0.03)$ than those measured in the nonsmokers $(345 \pm 65 \mathrm{pmol} / \mathrm{l})$. The authors have found no association between $\mathrm{F}_{2}$-isoprostane levels and age, sex, weight, height, the number of pack of cigarettes smoked per year, and the number of cigarettes smoked per day, or the nicotine and tar content of the smoked cigarettes. In that study, levels of $\mathrm{F}_{2}$-isoprostane metabolite excretion in urine have also been measured. In the smokers $(870 \pm 509 \mathrm{pmol} / \mathrm{mmol}$ of creatinine), levels of $\mathrm{F}_{2}$-isoprostane metabolites in urine were significantly $(\mathrm{p}=0.05)$ higher compared to the non-smokers group ( $415 \pm 155 \mathrm{pmol} / \mathrm{mmol}$ of creatinine). Moreover, there was a significant correlation $(\mathrm{p}<0.001)$ between free plasma $\mathrm{F}_{2}$-isoprostanes and their urinary metabolites in the smoker and non-smoker groups. No significant differences have been found between free $(p=0.43)$ and esterified $(p=20) F_{2}$-isoprostane levels in plasma samples obtained in the morning before the 1 st cigarette $(242 \pm 147 \mathrm{pmol} / \mathrm{l}$ and $574 \pm 217 \mathrm{pmol} / \mathrm{l}$ respectively) and samples obtained immediately after 30 -min period during which a participant smoked 3 cigarettes $(237 \pm 117 \mathrm{pmol} / \mathrm{l}$ and $624 \pm 214 \mathrm{pmol} / \mathrm{l})$. However, after 2 weeks of abstinence from smoking, levels of free and esterified $\mathrm{F}_{2}$-isoprostanes were significantly lower than during smoking.

Obata et al. have also investigated the influence of smoking status on isoprostane contents [17]. They collected urine samples from 81 smoking men, 39 non-smokers and 21 ex-smokers and measured levels of 8-epi-PGF ${ }_{20}$. Levels of 8-epi-PGF ${ }_{2 \alpha}$ differed significantly between the samples collected from the smokers and the non-smokers. Levels in the smokers samples $(605.2 \pm 59.01 \mathrm{ng} / \mathrm{mg}$ creatinine) were significantly $(\mathrm{p}<0.05)$ higher, than in the samples of non-smokers $(424 \pm 70.37 \mathrm{ng} / \mathrm{mg}$ creatinine), while levels of 8-epi-PGF ${ }_{2 \alpha}$ in the ex-smoker samples $(487 \pm 98.48 \mathrm{ng} / \mathrm{mg}$ creatinine) did not differ significantly from the smokers or non-smokers samples. Obata et al. have not found a correlation between levels of 8-epi-PGF ${ }_{2 \alpha}$ and age of smokers, duration of smoking and the number of cigarettes smoked per day, however, they have found a weak negative correlation between urine isoprostane levels and age of the non-smokers and time since quitting smoking in the ex-smokers [17]. A strong positive correlation between 8-epi-PGF ${ }_{2 \alpha}$ urinary levels and smoking status has been also found by Keaney et al. $(p<0.0001)$ [14].

Reilly et al. [18] have investigated levels of isoprostanes in urine of patients with homozygous familial hypercholesterolemia (HFH) and moderate hypercholesterolemia (HC). They performed 3 studies: in the 1st one, in $38 \mathrm{HFH}$ subjects, urinary isoprostane excretion was measured. In the 2nd study, levels of $i_{2 a} F_{2 a}$ III adjusted for LDL protein in unstimulated LDL in samples from $\mathrm{HFH}$ patients were measured, and in the 3rd study, they measured urinary levels of $\mathrm{F}_{2}$-isoprostanes in $\mathrm{HC}$ patients.

Those authors have found that urinary $\mathrm{iPF}_{2 \alpha}-\mathrm{III}$ was higher in the $\mathrm{HFH}$ patients $(85 \pm 5.5 \mathrm{pmol} / \mathrm{mmol}$ 
creatinine, $\mathrm{p}<0.0005)$ compared with the age- and sexmatched normocholesterolemic controls $(58 \pm 4.2 \mathrm{pmol} /$ mmol creatinine). There has also been a significant correlation $(\mathrm{p}<0.02)$ between urinary $\mathrm{iPF}_{2 \alpha}$-III levels and serum cholesterol in the samples from HFH patients. This correlation has not been observed in the control patients. Similarly, $\mathrm{iPF}_{2 a}-\mathrm{VI}$ urinary levels were higher in the HFH patients $(281 \pm 22 \mathrm{pmol} / \mathrm{mmol}$ creatinine) compared to the controls (175 $\pm 13 \mathrm{pmol} / \mathrm{mmol}$ creatinine, $\mathrm{p}<0.0001)$. Levels of urinary $\mathrm{iPF}_{2 \alpha}$-III esterified in the LDL samples from the $\mathrm{HFH}$ patients $(\mathrm{N}=16,1.09 \pm 0.08 \mathrm{pmol} / \mathrm{mmol}$ creatinine) were significantly higher than in the control participants $(\mathrm{N}=16,0.4 \pm 0.03 \mathrm{pmol} / \mathrm{mmol}$ creatinine, $\mathrm{p}<0.0001)$. There have been no significant correlations between urinary $\mathrm{F}_{2}$-isoprostanes and age, sex and a history of the use of lipid-lowering agents in the HFH patients [18].

\section{NEUROLOGICAL DISEASES}

It is suggested that oxidative stress and lipid peroxidation have a role in neurodegenerative diseases. There is an increasing number of evidence that free radicals damage brain lipids, carbohydrates, proteins and DNA, which is involved in neuron death in neurodegenerative disorders. There is a hypothesis, according to which, oxidative stress plays an important role in the pathogenesis of neuron degeneration in Alzheimer disease (AD) and a large number of studies confirm this hypothesis [19]. A number of studies have also shown that oxidative stress affects many clinical features of Down syndrome (DS) [20].

Praticò et al. [21] have investigated levels of 8,12-iso$\mathrm{iPF}_{2 \alpha}-\mathrm{VI}$ in cerebrospinal fluid (CSF), urine and plasma of 24 participants. In the samples collected from patients with probable or possible $\mathrm{AD}$, urinary, plasma and CSF levels of 8,12 -iso-iPF ${ }_{2 \alpha}$-VI were significantly higher than in controls $(4.93 \pm 0.42 \mathrm{ng} / \mathrm{mg}$ creatinine, $4.18 \pm 0.56 \mathrm{ng} / \mathrm{mg}$ creatinine respectively vs. $1.77 \pm 0.17 \mathrm{ng} / \mathrm{mg}$ creatinine) $(\mathrm{p}<0.0001)$. Moreover, there was a correlation between CSF and urinary levels of 8,12-iso-iPF ${ }_{2 \alpha}-\mathrm{VI}$ and between CSF and plasma levels of 8,12-iso-iPF ${ }_{2 \alpha}-\mathrm{VI}(\mathrm{p}<0.001)$ [21].

In 1998 Praticò et al. [22] investigated brain tissue samples obtained by autopsy from 19 patients with $\mathrm{AD}, 6$ with Parkinson disease (PD), 10 with schizophrenia (SCHI) and 8 controls. The samples were collected from brain frontal pole (FP), temporal pole (TP) and cerebellum. Levels of $\mathrm{iPF}_{2 \alpha}$-III in the FP of the AD brains were significantly higher (240-880 pg/g wet tissue, median (Me) $=410 \mathrm{pg} / \mathrm{g}$ wet tissue) compared to the samples from PD and controls $(80-300 \mathrm{pg} / \mathrm{g}$ wet tissue, $\mathrm{Me}=230 \mathrm{pg} / \mathrm{g}$ wet tissue, $\mathrm{p}=0.004)$. Increased levels of $\mathrm{iPF}_{2 \alpha}$-III were also found in the TP from the AD brains (250-685 pg/g wet tissue, $\mathrm{Me}=445 \mathrm{pg} / \mathrm{g}$ wet tissue) compared to the controls (110-300 pg/g wet tissue, $\mathrm{Me}=205 \mathrm{pg} / \mathrm{g}$ wet tissue). There were no statistically significant correlations between age, postmortem interval, disease duration and $\mathrm{PFF}_{2 \alpha}-\mathrm{III}$ levels in the FP and TP samples from the $\mathrm{AD}$ brains.

Levels of 8,12-iso-iPF ${ }_{2 a}$-VI have been also measured in urine samples collected from patients with Down syndrome (DS) [20]. Thirty three samples from subjects with DS and 33 from controls were collected. In the samples from DS subjects, levels of 8,12-iso-iPF ${ }_{2 \alpha}$-VI were significantly higher $0.75-4.25 \mathrm{ng} / \mathrm{mg}$ creatinine, $\mathrm{Me}=1.97 \mathrm{ng} / \mathrm{mg}$ creatinine) than in the healthy controls $(0.25-2.5 \mathrm{ng} / \mathrm{mg}$ creatinine, $\mathrm{Me}=1.2, \mathrm{p}<0.01)$. There were no differences between the DS male and female participants. In the DS subjects, there has been a significant correlation between urinary levels of this isoprostane and age of the participants $(p=0.002)$, but this correlation has not been found in the healthy controls [20].

\section{ASTHMA}

Asthma is a common chronic respiratory disease [23], characterized by chronic airways inflammation and oxidative stress [24]. Elevated airways inflammation often precedes the onset of symptoms or airway limitation [25]. 
As inflammation is often associated with an increased generation of ROS, it is reasonable to suppose that oxidative stress could be mechanistically involved in asthma [26].

Quantification of airways inflammation is difficult because it requires invasive techniques. On the other hand, concentration of oxidative stress biomarkers in plasma or urine may reflect systemic inflammation rather than lung inflammation. Bronchoscopy with biopsy remains the gold standard for assessing airways inflammation, but its invasiveness makes it unethical as a routine method, particularly in children [24].

There is an increasing interest in measuring exhaled breath condensate $(\mathrm{EBC})$ in subjects with pulmonary disease. The analysis of EBC is a noninvasive method, which is used to monitor lung inflammation and, which shows local production of free radicals [27]. The safety of EBC has been shown in both adults and children. It has been demonstrated that collection of EBC is $100 \%$ successful starting from the 4th year of age [28].

Balanza et al. [24] have investigated isoprostane levels in exhaled breath condensate of healthy and asthmatic children. The participants were divided in 3 groups. In the first group there were 22 nonatopic children, in the second group - 30 children with episodic asthma and in the third group - 10 children with moderate persistent asthma. Mean concentrations of 8-isoprostane in EBC were increased in the asthmatic children $(18.3 \mathrm{pg} / \mathrm{ml})$ compared to the healthy controls $(6.59 \mathrm{pg} / \mathrm{ml}, \mathrm{p}<0.026)$. Levels of 8-isoprostanes in EBC were also significantly increased in the children with moderate persistent asthma $(36.25 \mathrm{pg} / \mathrm{ml})$ compared to the children with episodic asthma $(12.28 \mathrm{pg} / \mathrm{ml}, \mathrm{p}<0.012)$ and to the healthy controls. The children with episodic asthma $(12.28 \mathrm{pg} / \mathrm{ml}) \mathrm{had}$ also significantly higher levels of 8-isoprostanes in EBC compared to the healthy participants $(6.59 \mathrm{pg} / \mathrm{ml}$, $\mathrm{p}<0.0001)$ [24].

Also Baraldi et al. have investigated levels of isoprostanes in EBC of asthmatic children [29]. They collected samples from 12 healthy children, 12 steroid-naïe asthmatic children and 30 children with mild-to-moderate persistent asthma who were treated with inhaled corticosteroids (ICSs). Levels of 8-isoprostane were increased in EBC of both groups of asthmatic children - the steroid naive $(56.4 \pm 7.7 \mathrm{pg} / \mathrm{ml}, \mathrm{p}<0.01)$ and the steroidtreated $(47.2 \pm 2.3 \mathrm{pg} / \mathrm{ml}, \mathrm{p}<0.05)$ compared to the controls $(34.2 \pm 4.5 \mathrm{pg} / \mathrm{ml})$, and there were no significant differences in the levels of EBC 8-isoprostane between the 2 groups of asthmatic children $(\mathrm{p}=0.14)$ [29]. Zanconato et al. [30] have measured 8-isoprostane levels in EBC of 19 healthy control children, 14 steroid-naïve children with mild persistent asthma, 13 ICSs treated children with mild-to-moderate persistent asthma and 9 children with unstable asthma. They have found that EBC 8-isoprostane levels were higher in samples from the 3 groups of asthmatic children (respectively: $16.2 \mathrm{pg} / \mathrm{ml}, \mathrm{p}<0.001 ; 18.1 \mathrm{pg} / \mathrm{ml}, \mathrm{p}<0.001$ and $29.7 \mathrm{pg} / \mathrm{ml}$, $\mathrm{p}<0.01)$ compared with the controls $(3.5 \mathrm{pg} / \mathrm{ml})$ and, as in Baraldi et al. study [29], there were no differences in 8 -isoprostane levels between the 3 groups of asthmatic children.

Montuschi et al. (31) have measured concentrations of 8-isoprostane in EBC of 10 healthy adults, 12 patients with mild asthma, 17 adults with moderate asthma and 15 with severe asthma [31]. Concentrations of EBC 8 -isoprostane were increased in the patients with mild $(33.7 \pm 2.8 \mathrm{pg} / \mathrm{ml}, \mathrm{p}<0.01)$, moderate $(38.3 \pm 3.7 \mathrm{pg} / \mathrm{ml}$, $\mathrm{p}<0.001)$ and severe $(49.1 \pm 5 \mathrm{pg} / \mathrm{ml}, \mathrm{p}<0.001)$ asthma compared to the healthy subjects $(15.8 \pm 1.6 \mathrm{pg} / \mathrm{ml})$. The highest levels of 8 -isoprostane were found in the samples from severe asthma compared to the mild and moderate asthma samples. It has been also found that EBC levels of 8-isoprostane in the samples from mild asthma patients correlated with exhaled nitric oxide (NO) $(\mathrm{p}<0.05)[31]$.

Table 1 shows a summary of diseases in which increased levels of isoprostanes have been found. 
Table 1. Diseases in which the increased levels of isoprostanes have been found

\begin{tabular}{llc}
\hline \multicolumn{1}{c}{ Disease } & \multicolumn{1}{c}{ Sample } & Reference \\
\hline Risk factors for heart disease & & \\
NIDDM & plasma & 12 \\
& urine & 13 \\
IDDM & urine & 13,14 \\
obesity & urine & 14 \\
smoking & plasma & 3 \\
& urine & 17,14 \\
HFH & urine & 18 \\
Neurological diseases & & \\
AD & CSF, urine, plasma & 21 \\
& brain tissue samples & 22 \\
DS & urine & 20 \\
Pulmonary diseases & & \\
asthma & EBC & $24,30,31$ \\
\hline
\end{tabular}

NIDDM - non-insulin dependent diabetes mellitus; IDDM - insulin dependent diabetes mellitus; HFH - homozygous familial hypercholesterolemia; AD - Alzheimer disease; DS - Down syndrome; CSF cerebrospinal fluid; EBC - exhaled breath condensate.

\section{COMPARISON OF ISOPROSTANES}

\section{TO OTHER OXIDATIVE STRESS BIOMARKERS}

Some studies have been carried out to compare isoprostanes as oxidative stress markers to other available markers. Il'yasowa et al. [32] have used doxorubicinbased chemotherapy as a clinical model of oxidative assault in humans. They collected urine samples from chemotherapy patients $(\mathrm{N}=23)$ before $(\mathrm{T} 0)$ and $1 \mathrm{~h}(\mathrm{~T} 1)$ and $24 \mathrm{~h}$ (T24) after administration of treatment. Levels of allantoin and isoprostanes (iPF(2 $\alpha)$-III, iPF(2 $\alpha$ )-VI, 8,12-iso-iPF(2 $\alpha$ )-VI and 2,3-dinor-iPF(2 $\alpha)$-III) were measured using the liquid chromatography - mass spectrometry (LC-MS). As a result, levels of the examined biomarkers were higher in T1 samples compared to the samples T0: the difference was statistically significant in the case of isoprostanes and of borderline significance in the case of allantoin (Table 2).
Table 2. Differences in the levels of isoprostanes and allantoin in $\mathrm{T} 1$ samples compared to $\mathrm{T} 0$ [32]

\begin{tabular}{lcc}
\hline \multicolumn{1}{c}{ Biomarker } & $\begin{array}{c}\text { Increase } \\
{[\%]}\end{array}$ & $\mathrm{p}$ \\
\hline Isoprostane & & \\
$\operatorname{iPF}(2 \alpha)$-III & 62 & $<0.05^{*}$ \\
$\operatorname{iPF}(2 \alpha)$-VI & 41 & $<0.05^{*}$ \\
8,12 -iso-iPF $(2 \alpha)$-VI & 58 & $<0.05^{*}$ \\
2,3-dinor-iPF(2 $\alpha)$-III & 52 & $<0.05^{*}$ \\
Allantoin & 22 & $0.06^{* *}$ \\
\hline
\end{tabular}

Urine samples from chemotherapy patients: $\mathrm{T} 0$ - collected before administration of treatment; $\mathrm{T} 1$ - collected after $1 \mathrm{~h}$ of administration of treatment.

* Statistically significant.

** Borderline significant.

Researchers have also observed, that in the samples taken $24 \mathrm{~h}$ after administration of the treatment (T24) levels of isoprostanes returned to their baseline levels ( $\mathrm{T} 0$ ), while levels of allantoin continued to increase. However, the difference between the levels of allantoin at T0 and T24 was not statistically significant.

Roberts et al. [9] have compared the amounts of MDA and esterified $\mathrm{F}_{2}$-isoprostanes formed in the liver of rats after administration of $\mathrm{CCl}_{4}$, which is a classic model compound form inducing free radical damage in the liver [33]. As an index of severity of liver injury they measured levels of serum glutamic pyruvic transaminase (SGPT). The resultant levels of $\mathrm{F}_{2}$-IsoPs in the liver increased strikingly by approximately 85 -fold, which was accompanied by an increase of SGPT in plasma. In contrast, levels of MDA increased only less than 3-fold.

Summarizing, the increase in both, MDA and $\mathrm{F}_{2}$-IsoPs, levels was correlated with oxidation of microsomal lipids in vitro, but the relative increase in the levels of $\mathrm{F}_{2}$-IsoPs was much higher than in the levels of MDA. This demonstrates a very good correlation between the amount of $\mathrm{F}_{2}$ IsoPs production and severity of hepatocellular injury [9]. Sensitivity and specify of oxidant stress biomarkers have also been investigated in the Biomarkers of 
Table 3. Effect of $\mathrm{CCl}_{4}$ on oxidation products in rat plasma and urine [33]

\begin{tabular}{|c|c|c|c|c|c|c|c|c|}
\hline \multirow{4}{*}{ Biomarker } & \multirow{4}{*}{ Method } & \multirow{4}{*}{ Medium } & \multicolumn{6}{|c|}{ Time points after $\mathrm{CCl}_{4}$ administration } \\
\hline & & & \multicolumn{2}{|c|}{$2 \mathrm{~h}$} & \multicolumn{2}{|c|}{$7 \mathrm{~h}$} & \multicolumn{2}{|c|}{$16 \mathrm{~h}$} \\
\hline & & & \multicolumn{6}{|c|}{$\begin{array}{c}\text { dose of } \mathrm{CCl}_{4} \\
{[\mathrm{mg} / \mathrm{kg}]}\end{array}$} \\
\hline & & & 120 & 1200 & 120 & 1200 & 120 & 1200 \\
\hline TBA & TBARS & plasma & $x$ & $x$ & $x$ & $x$ & $x$ & * \\
\hline MDA & TBA 3rd derivative & plasma & $*$ & * & $x$ & * & $*$ & $x$ \\
\hline MDA & GC-MS & plasma & $*$ & * & * & * & $x$ & $x$ \\
\hline Free + esterified 8-iso-PGF $2 a$ & GC-MS & plasma & $*$ & * & * & * & $*$ & * \\
\hline Free 8-iso-PGF2a & GC-MS & plasma & * & * & $x$ & * & $x$ & * \\
\hline MDA & HPLC with spectrophotometry & urine & $x$ & $x$ & * & * & $x$ & * \\
\hline Free + esterified 8-iso-PGF $2 a$ & immunoassay & urine & $x$ & $x$ & * & * & * & * \\
\hline 8,12-iso-iPF2a-VI & LC/MS/MS & urine & - & - & * & * & * & $*$ \\
\hline 8-OHdG & immunoassay & urine & - & - & $x$ & * & $*$ & $*$ \\
\hline
\end{tabular}

TBARS - thiobarbituric acid reactive substance; MDA - malondialdehyde; TBA - thiobarbituric acid; GC-MS - gas chromatography-mas spectrometry; HPLC - high performance liquid chromatography; LC/MS/MS - liquid chromatography tandem mas spectrometry.

" $\times$ " No statistically significant differences between $\mathrm{CCl}_{4}$ treatment rats and controls at the same time point.

"-" No measurements were performed because of too low urine production at $2 \mathrm{~h}$ point.

* Statistically significant differences between $\mathrm{CCl}_{4}$ treatment rats and controls at the same time point.

Oxidative Stress Study (BOSS) organized and sponsored by The National Institute of Environmental Health Sciences (NIEHS) [33]. The 2nd report of this multilaboratory study, presents results based on using $\mathrm{CCl}_{4}$ as a compound inducing oxidative stress in the liver. In this experiment 344 male Fisher rats were administered intraperitoneal injections of carbon tetrachloride in canola oil $(120 \mathrm{mg} / \mathrm{kg}$ or $1200 \mathrm{mg} / \mathrm{kg})$. Control rats received an equal volume of canola oil. Plasma and urine were collected in 3 time points: 2,7 and $16 \mathrm{~h}$ after $\mathrm{CCl}_{4}$ injections. Each group consisted of 5 rats for each anlysis. The selected results with statistically significant values compared to the controls are marked in Table 3.

The authors have concluded that MDA and 8-iso- $\mathrm{PGF}_{2 \alpha^{\prime}}$ measured in plasma by the GC/NICI/MS method, are relevant biomarkers of oxidative stress and both assays are highly reproducible, sensitive, specific and applicable to stored specimens. Urinary isoprostanes measured by immunoassay are noninvasive and promising markers of $\mathrm{CCl}_{4}$-induced damage in rats.

The results of this study also indicate that levels of isoprostanes remain elevated at least for $16 \mathrm{~h} \mathrm{[33].}$

\section{OCCUPATIONAL AND ENVIRONMENTAL FACTORS THAT INCREASE THE LEVEL OF ISOPROSTANES}

Barregard et al. [34] have investigated the influence of wood smoke - one of the sources of particulate air pollution - on inflammatory markers, coagulation factors and lipid peroxidation. They recruited 6 healthy never-smoker men and 7 healthy never-smoker women aged 20-56. The subjects were divided in 2 rounds -7 and 6 people, respectively. For 8-iso- $\mathrm{PGF}_{2 \alpha}$ there were only 4 subjects in round 1 . After taking blood and urine samples, the subjects were exposed to filtered indoor air for $4 \mathrm{~h}$ in exposure chamber 1, and to wood smoke 1 week later, also for $4 \mathrm{~h}$. Blood and urine samples were taken also after leaving 
the exposure chamber and the next morning. The levels of urinary 8-iso- $\mathrm{PGF}_{2 \alpha}$ were measured using the radioimmunoassay method.

The authors have found, that levels of 8 -iso- $\mathrm{PGF}_{2 \alpha}$ in urine were higher after wood-smoke exposure than after clean air, but the difference was not statistically significant. However, when the researchers rejected 1 outlier, which had a high excretion of 8-iso- $\mathrm{PGF}_{2 \alpha}$ in a sample before wood smoke exposure, the mixed effect analysis of variance (ANOVA) model showed a significant increase in excretion of 8-iso- $\mathrm{PGF}_{2 \alpha}$ in the morning after wood smoke exposure $(p=0.03$ for excretion corrected for creatinine) [34].

The role of tobacco smoke and occupational exposure to air-formaldehyde in the induction of oxidative stress status has been investigated by Romanazzi et al. [35]. In this study 51 healthy men were involved. They had been working in an industry of decorative laminates so they were potentially exposed to formaldehyde (FA). Control group of 54 males was recruited from some offices and laboratories where FA was not used.

For each subject, the 1st morning urine samples were collected for urinary 15-F2t IsoP and cotinine determination, and air-FA samples, which were passively collected for an entire working shift. 15-F2t IsoP in urine was measured using the enzyme-linked immunosorbent assay (ELISA) kit. As a result, significantly higher levels of $15-\mathrm{F} 2 \mathrm{t}$ IsoP in urine from the males exposed to FA and smokers $(3.1 \pm 1.4 \mathrm{mg} / \mathrm{mg}$ creatinine) than in urine from the non-exposed males and non-smokers $(1.2 \pm 0.6 \mathrm{ng} / \mathrm{mg}$ creatinine) were found. The authors say, that in the case of isoprostanes, smoking effect is not significantly different from the FA effect: in the group of non-exposed smokers, the level of isoprostanes was $1.8 \pm 1 \mathrm{ng} / \mathrm{mg}$ creatinine, while the level of isoprostanes in the exposed nonsmokers was $2 \pm 1.2 \mathrm{ng} / \mathrm{mg}$ creatinine. In summary, it can be said, that FA exposure can increase oxidative stress status as well as tobacco smoking can, therefore, the authors suggest that primary prevention of professional and environmental exposure to FA and tobacco smoke plays an important role for health care [35].

Lehtonen et al. [36] have investigated whether inflammatory markers and nitric oxide (NO) in exhaled breath condensate (EBC) could be used to assess inflammation in asbestosis. All patients in this research have been diagnosed to have asbestosis. They were all men, with average exposure to asbestos of 20.5 years (range 10-39 years), they were aged 56-74 years and exposure to asbestos had stopped 1439 years before the study. Control group were 15 males aged 53-73 years, all of them were non-smokers and all had normal spirometric values and no respiratory symptoms according to the symptoms questionnaire. The level of isoprostanes in EBC was measured by immunoassay.

As a result, it has been found, that the patients with asbestosis had an increased concentration of 8-isoprostane and $\mathrm{NO}$ in exhaled breath condensate in comparison with the healthy controls. The authors suggest, that the measurement of exhaled NO, and analysis of inflammatory markers in the $\mathrm{EBC}$ could be a promising, non-invasive method of measuring lung inflammation in patients with asbestosis. They also suggest, that further studies are needed to clarify whether progression of the disease or responsiveness to anti-inflammatory treatment can be evaluated or predicted by these methods [36].

\section{BIOLOGICAL ACTIVITY}

It has been found that isoprostanes are not just oxidative stress markers. They are also biologically active. Isoprostanes released from cell membranes by phospholipases circulate in the plasma in free forms and, therefore, can activate membrane receptors [37]. 15- $\mathrm{F}_{2 \mathrm{t}}$-IsoP is a partial agonist at the prostanoid TP receptor on platelets and, therefore, it might inhibit the pro-aggregatory effects of TP receptor stimulation [38].

Janssen et al. have investigated excitatory effect of 8-iso-PGF ${ }_{2 \alpha}$, 8-iso- $\mathrm{PGF}_{2 \beta}$ and 8-iso- $\mathrm{PGF}_{3 \alpha}$ on human 
airways smooth muscle [39]. In that study, segments of human main-stem bronchi were collected. Both 8-iso-PGF ${ }_{2 \alpha}$ and 8-iso- $\mathrm{PGF}_{2 \beta}$ produced concentration-dependent contractions of smooth muscle from human large and small airways [39].

Oliviera et al. have examined the influence of isoprostanes on human umbilical artery (HUA) in vitro [40]. Sections of umbilical cord were obtained from the placenta. Measurable contractions were produced by 8 -iso- $\mathrm{PGE}_{2}$, 8-iso-PGE 1 , 8-iso-PGF ${ }_{1 \alpha}$, 8-iso- $\mathrm{PGF}_{2 \alpha}$, 8-iso-PGF ${ }_{2 \beta}$.

In a study by Sametz et al. [41], the contracting activity of 8-iso-PGF ${ }_{2 \alpha}$ and 8-iso- $\mathrm{PGE}_{2}$ was measured in the isolated rat gastric fundus, isolated rat aorta and the isolated guineapig ileum in comparison to the thromboxane (TX) $\mathrm{A}_{2}$-mimetic $\mathrm{U} 46619$ and the traditional prostaglandin $\mathrm{PGE}_{2}$ [37]. In the isolated rat aorta 8-iso-PGE 2,8 -iso-PGF ${ }_{2 \alpha}$ induced vasoconstrictions in a concentration-dependent manner. By comparison of the $\mathrm{pEC}_{50}$ values the following rank order of potency was determined: $\mathrm{U} 46619>8$-iso- $\mathrm{PGE}_{2}>$ 8-iso-PGF $\mathrm{PG}_{2 \alpha}>\mathrm{PGE}_{2}$. In the isolated rat gastric fundus, the rank order of potency determined by comparison of the $\mathrm{pEC}_{50}$ was: $\mathrm{PGE}_{2}>8$-iso- $\mathrm{PGE}_{2}>\mathrm{U} 46619>$ 8-iso-PGF ${ }_{2 a}$. In the isolated guinea-pig ileum, U 46619 and 8-iso-PGF ${ }_{2 \alpha}$ had no effect, while $\mathrm{PGE}_{2}, 8$-iso-PGE 2 caused a concentration-dependent contraction [41].

\section{CONCLUSIONS}

Isoprostanes are nowadays in common use. Researchers have proven that they are reliable oxidative stress markers. Their elevated levels were found in biological samples from the patients with a number of cardiovascular disease risk factors, such as diabetes [12-15], obesity [14,16], hypercholesterolemia [18] and smokers [17]. Also in cerebrospinal fluid, urine and plasma collected from the patients with probable or possible $\mathrm{AD}$, levels of isoprostanes were significantly higher compared to the controls [21]. Praticò et al. have also found higher levels of isoprostanes in temporal pole and frontal pole in brain tissue samples obtained by autopsy from the patients with $\mathrm{AD}$ compared to the controls and compared to the brain tissue samples collected from the patients with PD [22]. In the urine samples from the patients with down syndrome, the levels of isoprostanes were also significantly higher compared to the controls [20]. These results may confirm the hypothesis that oxidative stress and lipid peroxidation may play an important role in neurodegenerative diseases.

Measured levels of isoprostanes in exhaled breath condensate may be an alternative for bronchoscopy, because they show local production of free radicals and allow monitoring lung inflammation. Higher levels of isoprostanes in EBC have been found by Balanza in the patients with nonatopic, episodic and moderate persistent asthma compared to the controls [24]. The highest concentration of these 3 groups was found in the samples from moderate persistent asthma [24]. Balardi et al. have also found higher levels of isoprostanes in ECB collected from the patients with asthma (steroid-naïve asthmatic children and children with mild-to-moderate persistent asthma who were treated with ICSs) compared to the controls, but they have not found differences in isoprostane levels between the 2 groups [30].

Also Zanconato has not found differences in EBC isoprostanes levels between the 3 groups of asthmatic children (steroid-naive children with mild persistent asthma, ICSs treated children with mild-to-moderate persistent asthma, children with unstable asthma) but, like in other studies, levels of EBC isoprostanes in these 3 groups were higher than in the control group [30].

In Montuschi's research, the highest levels of EBC isoprostanes have been found in the adults with severe asthma compared with the samples from adults with mild asthma, moderate asthma and control group [31].

Isoprostanes also have a biological activity. It has been found that isoprostanes produce concentration dependent contractions of smooth muscle from human large and 
small airways [39] and of human umbilical artery in vitro [40]. They also induce vasoconstrictions [41]. Biological activity of isoprostanes requires further studies because due to it they are likely to have other applications in addition to their use as oxidative stress markers.

Discovery of isoprostanes makes it possible to assess the role of ROS in human physiology and pathophysiology [42]. Development of methods for determination of IsoP characterized by high specificity and sensitivity made it possible to conduct numerous studies on the role of ROS in a number of diseases.

\section{REFERENCES}

1. Cracowski JL, Durand T, Bessard G. Isoprostanes as a biomarker of lipid peroxidation in humans: Physiology, pharmacology and clinical implications. Trends Pharmacol Sci. 2002;23(8):360-6, http://dx.doi.org/10.1016/S0165-6147 (02)02053-9.

2. Voynow JA, Kummarapurugu A. Isoprostanes and asthma. Biochim Biophys Acta. 2011;1810:1091-5, http://dx.doi. org/10.1016/j.bbagen.2011.04.016.

3. Morrow JD, Frei B, Longmire AW, Gaziano M, Lynch SM, Shyr Y, et al. Increase in circulating products of lipid peroxidation ( $\mathrm{F}_{2}$-isoprostanes) in smokers. New Engl J Med. 1995;332:1198-203, http://dx.doi.org/10.1056/ NEJM199505043321804.

4. Milne G, Yin H, Jason D. Human biochemistry of the isoprostane pathway. J Biol Chem. 2008;283:15533-7, http:// dx.doi.org/10.1074/jbc.R700047200.

5. Tokarz A, Jelińska M, Ozga A. [Isoprostanes - New biomarkers in lipid peroxidation in vivo?]. Biul Wydz Farm AMW. 2004;2:10-7. Polish.

6. Musiek ES, Brooks JD, Joo M, Brunoldi E, Porta A, Zanoni $\mathrm{G}$, et al. Electrophilic cyclopentanone neuroprostanes are anti-inflammatory mediators formed from the peroxidation of the $\omega-3$ polyunsaturated fatty docosahexaenoic acid. J Biol Chem. 2008;183(29):19927-35, http://dx.doi. org/10.1074/jbc.M803625200.
7. Song WL, Paschos G, Fries S, Reilly M, Yu Y, Rokach J, et al. Novel eicosapentaenoic acid-derived $\mathrm{F}_{3}$-isoprostanes as biomarkers of lipid peroxidation. J Biol Chem. 2009;284(35):23636-43, http://dx.doi.org/10.1074/jbc. M109.024075.

8. Montuschi P, Barnes P, Jackson R II. Insights into oxidative stress: The isoprostanes. Curr Med Chem. 2007;14:703-17, http://dx.doi.org/10.2174/092986707780059607.

9. Roberts LJ, Morrow JD. Measurement of $\mathrm{F}_{2}$-isoproastanes as index of oxidative stress in vitro. Free Radic Biol Med. 2000;28:505-13, http://dx.doi.org/10.1016/S0891-5849 (99)00264-6.

10. Praticò D, Lawson JA, Rokach J, FitzGerald GA. The isoprostanes in biology and medicine. Trends Endocrinol Metab. 2001;12(6):243-7, http://dx.doi.org/10.1016/S10432760(01)00411-8.

11. Milne GL, Musiek ES, Morrow JD. $F_{2}$-isoprostanes as markers of oxidative stress in vivo: An overview. Biomarkers. 2005;10:S10-23, http://dx.doi.org/10.1080/1354750050 0216546.

12. Gopaul NK, Änggård EE, Mallet AI, Betteridge DJ, Wolff SP, Nouroo-Zadeh J. Plasma 8-epi-PGF ${ }_{2 \alpha}$ levels are elevated in individuals with non-insulin dependent diabetes mellitus. FEBS Lett. 1995;368:225-9, http://dx.doi. org/10.1016/0014-5793(95)00649-T.

13. Davì G, Ciabattoni G, Consoli A, Mezzetti A, Falco A, Santarone S, et al. In vivo formation of 8-iso-prostaglandin $\mathrm{F}_{2 a}$ and platelet activation in diabetes mellitus: Effect of improved metabolic control and vitamin E supplementation. Circulation. 1999;99:224-9, http://dx.doi.org/10.1161/01. CIR.99.2.224.

14. Keaney JF, Larson MG Jr., Vasan RS, Wilson PWF, Lipinska I, Corey D, et al. Obesity and systemic oxidative stress: Clinical correlates of oxidative stress in the Framingham Study. Arterioscler Thromb Vasc Biol. 2003;23:434-9, http:// dx.doi.org/10.1161/01.ATV.0000058402.34138.11.

15. Davì G, Chiarelli F, Santilli F, Pomilio M, Vigneri S, Falco A, et al. Enhanced lipid peroxidation and platelet 
activation in the early phase of type 1 diabetes mellitus: Role of interleukin-6 and disease duration. Circulation. 2003;107:3199-203, http://dx.doi.org/10.1161/01.CIR. 0000074205.17807.D0.

16. Davì G, Guagnano MT, Ciabattoni G, Basili S, Falco A, Marinopiccoli M, et al. Platelet activation in obese women. Role of inflammation and oxidant stress. JAMA. 2008;288 (16):2008-14, http://dx.doi.org/10.1001/jama.288.16.2008.

17. Obata T, Tomaru K, Nagakura T, Izumi Y, Kawamoto T. Smoking and oxidant stress: Assay of isoprostane in human urine by gas chromatography-mass spectrometry. J Chromatogr B Biomed Sci App. 2000;746:11-5, http://dx.doi. org/10.1016/S0378-4347(00)00182-1.

18. Reilly MP, Praticò D, Delanty N, DiMinno G, Tremoli E, Rader D, et al. Increased formation of distinct $\mathrm{F}_{2}$ isoprostanes in hypercholesterolemia. Circulation. 1998;98:2822-8, http://dx.doi.org/10.1161/01.CIR.98.25.2822.

19. Markesbery WR, Carney JM. Oxidative alterations in Alzheimer's disease. Brain Pathol. 1999;9:133-46, http://dx.doi. org/10.1111/j.1750-3639.1999.tb00215.x.

20. Praticò D, Iuliano L, Amerio G, Tang LX, Rokach J, Sabatino $\mathrm{G}$, et al. Down's syndrome is associated with increased 8,12-iso-iPF ${ }_{2 \alpha}$-VI levels: Evidence for enhanced lipid peroxidation in vivo. Ann Neurol. 2000;48:795-8, http://dx.doi.org/10.1002/1531-8249(200011)48:5<795:: AID-ANA15>3.0.CO;2-\#.

21. Praticò D, Clark CM, Lee VMY, Trojanowski JQ, Rokach J, FitzGerald GA. Increased 8,12-iso-iPF ${ }_{2 \alpha}$-VI in Alzheimer's disease: Correlation of noninvasive index of lipid peroxidation with disease severity. Ann Neurol. 2000;48:809-12, http://dx.doi.org/10.1002/1531-8249(200011)48:5<809: :AID-ANA19>3.0.CO;2-9.

22. Praticò D, Lee VMY, Trojanowski JQ, Rokach J, FitzGerald GA. Increased $\mathrm{F}_{2}$-isoprostanes in Alzheimer's disease: Evidence for enhanced lipid peroxidation in vivo. FASEB J. 1998;12(15):1777-83.

23. Jie Y, Isa ZM, Jie X, Ismail NH. Asthma and asthma-related symptoms among adults of an acid rain-plagued city in southwest China: Prevalence and risk factors. Pol J Environ Stud. 2013;22(3):711-26.

24. Balanzá SC, Aragones AM, Mir JCC, Ramírez JB, Ivánez R, Soriano $\mathrm{AN}$, et al. Leukotriene $\mathrm{B}_{4}$ and 8-isoprostane in exhaled breath condensate of children with episodic and persistent asthma. J Investig Allergol Clin Immunol. 2010;20(3):237-43.

25. Montuschi P, Martello S, Felli M, Mondino C, Barnes P, Chiarotti M. Liquid chromatography/mass spectrometry analysis of exhaled leukotriene $\mathrm{B}_{4}$ in asthmatic children. Respir Res. 2005;6:119, http://dx.doi.org/10.1186/1465-9921-6-119.

26. Dworski R. Oxidant stress in asthma. Thorax. 2000;55 Suppl 2: S51-3, http://dx.doi.org/10.1136/thorax.55.suppl_2.S51.

27. Kharitonov SA, Barnes PJ. Exhales markers of pulmonary disease. Am J Respir Crit Care Med. 2001;63:1693-722, http://dx.doi.org/10.1164/ajrccm.163.7.2009041.

28. Balardi E, Ghiro L, Piovan V, Carro S, Zacchello F, Zanconato S. Safety and success of exhaled breath condensate collection in asthma. Arch Dis Child. 2003;88:2358-60.

29. Baraldi E, Ghiro L, Piovan V, Carro S, Ciabattoni G, Barnes PJ, et al. Increased exhaled 8-isoprostane in childhood asthma. Chest. 2003;124:25-31, http://dx.doi. org/10.1378/chest.124.1.25.

30. Zanconato S, Carro S, Corradi M, Alinovi R, Pasquale MF, Baraldi E. Leukotriene and 8-isoprostane in exhaled breath condensate of children with stable and unstable asthma. J Allergy Clin Immunol. 2004;113:257-63, http://dx.doi. org/10.1016/j.jaci.2003.10.046.

31. Montuschi P, Corradi M, Ciabattoni G, Nightingale J, Kharitonov A, Barnes PJ. Increased 8-isoprostane, a marker of oxidative stress, in exhaled condensate of asthma patients. Am J Respir Crit Care Med. 1999;160:216-20, http://dx.doi. org/10.1164/ajrccm.160.1.9809140.

32. Il'yasowa D, Spasojevic I, Wang F, Tolun AA, Base K, Young SP, et al. Urinary biomarkers of oxidative status in a clinical model of oxidative assault. Cancer Epidemiol Biomarkers Prev. 2010;19(6):1506-10, http://dx.doi. org/10.1158/1055-9965.EPI-10-0211. 
33. Kadiiska MB, Gladen BC, Baird DD, Germolec D, Graham LB, Parker CE. Biomarkers of oxidative stress study II. Are oxidation products of lipids, proteins, and DNA markers of $\mathrm{CCl}_{4}$ poisoning? Free Radic Biol Med. 2005;38:698-710, http://dx.doi.org/10.1016/j.freerad biomed.2004.09.017.

34. Barregard L, Sällsten G, Gustafson P, Andersson L. Experimental exposure to wood-smoke particles in healthy humans: Effects on markers of inflammation, coagulation and lipid peroxidation. Inhal Toxicol. 2006;18:845-53, http:/ dx.doi.org/10.1080/08958370600685798.

35. Romanazzi V, Pirro V, Bellisario V, Mengozzi G, Paluso M, Pazzi M, et al. 15- $\mathrm{F}_{2 \mathrm{t}}$ isoprostanes as biomarker of oxidative stress induced by tobacco smoke and occupational exposure to formaldehyde in workers of plastic laminates. Sci Total Environ. 2013;442:20-5, http://dx.doi.org/10.1016/j.scitotenv.2012.10.057.

36. Lehtonen H, Oksa P, Lehtimäki L, Sepponen A, Nieminen $\mathrm{R}$, Kankaanranta $\mathrm{H}$, et al. Increased alveolar nitric oxide concentration and high levels of leukotriene $\mathrm{B}_{4}$ and 8-isoprostane in exhaled breath condensate in patients with asbestosis. Thorax. 2007;62:602-7, http://dx.doi.org/10.1136/ thx.2006.067868.
37. Cracowski JL. Isoprostanes: An emerging role in vascular physiology and disease? Chem Phys Lipids. 2004;128:75-83, http://dx.doi.org/10.1016/j.chemphyslip.2003.10.006.

38. Cranshaw JH, Evans TW, Mitchell JA. Characterization of the effects of isoprostane on platelet aggregation in human whole blood. Br J Pharmacol. 2001;132:1699-706, http:// dx.doi.org/10.1038/sj.bjp.0704019.

39. Janssen L, Premji M, Netherton S, Catalli A, Cox G, Keshavjee $\mathrm{S}$, et al. Excitatory and inhibitory actions of isoprostanes in human and canine airway smooth muscle. J Pharmacol Exp Ther. 2000;295:506-11.

40. Oliveira L, Stallwood NA, Crankshaw DJ. Effects of some isoprostanes on the human umbilical artery in vitro. Br J Pharmacol. 2000;129:509-14, http://dx.doi.org/10.1038/sj.bjp.0703083. 41. Sametz W, Hennerbichler S, Glaser S, Wintersteiger R, Juan H. Characterization of prostanoid receptors mediating actions of the isoprostanes, 8-iso- $\mathrm{PGE}_{2}$ and 8-iso-PGE ${ }_{2 \alpha}$, in some isolated smooth muscle preparations. Br J Pharmacol. 2000;130:1903-10, http://dx.doi.org/10.1038/sj.bjp.0703522.

42. Piłacik B, Wrońska-Nofer T, Wąsowicz W. F-isoprostanes biomarkers of lipid peroxidation: Their utility in evaluation of oxidative stress induced by toxic agents. Int J Occup Med Environ Health. 2002;15(1):19-27.

This work is available in Open Access model and licensed under a Creative Commons Attribution-NonCommercial 3.0 Poland License - http://creativecommons.org/ licenses/by-nc/3.0/pl/deed.en. 